\title{
EP-395 Unawareness hypoglycemia in patients with type 1 diabetes mellitus: prevalence and predictive clinical characteristics
}

Méndez Muros, Mariola; Cuéllar Lloclla, Eyveé Arturo, García Pérez, Fernando; Martínez de Pinillos Gordillo, Guillermo; Tomé-Fernández Ladreda, Mariana; García de Quirós Muñoz, Juan Manuel; Fernández Peña, José Ignacio; Fernández López, José Ignacio; Rivas Fernández, Margarita; Hidalgo Amat, Juana Magdalena; Durán García, Santiago; Cózar León, María Victoria.

Hospital Universitario Nuestra Señora de Valme

\section{OBJECTIVES}

The prevalence of unawareness hypoglycemia in patients with type 1 diabetes mellitus (T1DM) is uncertain. This study aims to determine its prevalence and predictive clinical characteristics with greater precision.

\section{METHODS}

Prospective study. 128 patients were recruited between September 2013 and January 2014. Awareness of hypoglycemia was assessed using the 'Clarke' questionnaire and was classified into two groups, depending on the presence (group 1) or absence (group 2) of symptoms perception.

\section{RESULTS}

\begin{tabular}{|c|c|}
\hline Population & $N=128$ \\
\hline Mean age & $36,2 \pm 12,8$ years \\
\hline Sex & $\begin{array}{c}53,8 \% \text { females } \\
48,2 \% \text { males }\end{array}$ \\
\hline Duration of diabetes & $15,65 \pm 9,18$ years \\
\hline HbA1c & $7,45 \% \pm 1,35$ \\
\hline $\begin{array}{l}\text { Intensive insulin therapy (basal + } \\
\text { bolus) }\end{array}$ & $87,5 \%$ \\
\hline Biphasic insulin & $12,5 \%$ \\
\hline
\end{tabular}

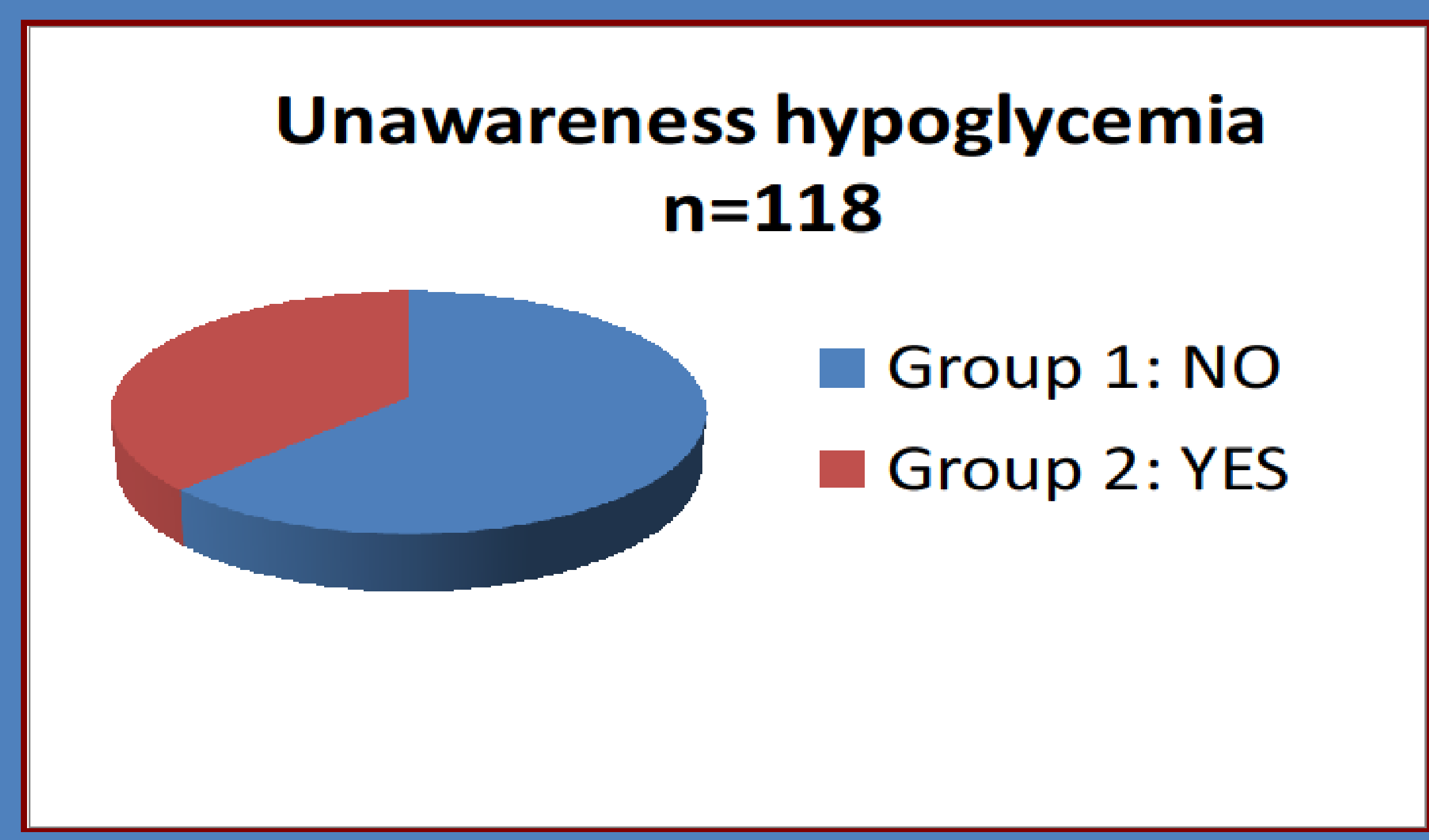

$\geq 1$ episodes of severe hypoglycemia during the previous year

$40,00 \%$

$35,00 \%$

$30,00 \%$

$25,00 \%$

$20,00 \%$

$15,00 \%$

$10,00 \%$

$5,00 \%$

$0,00 \%$

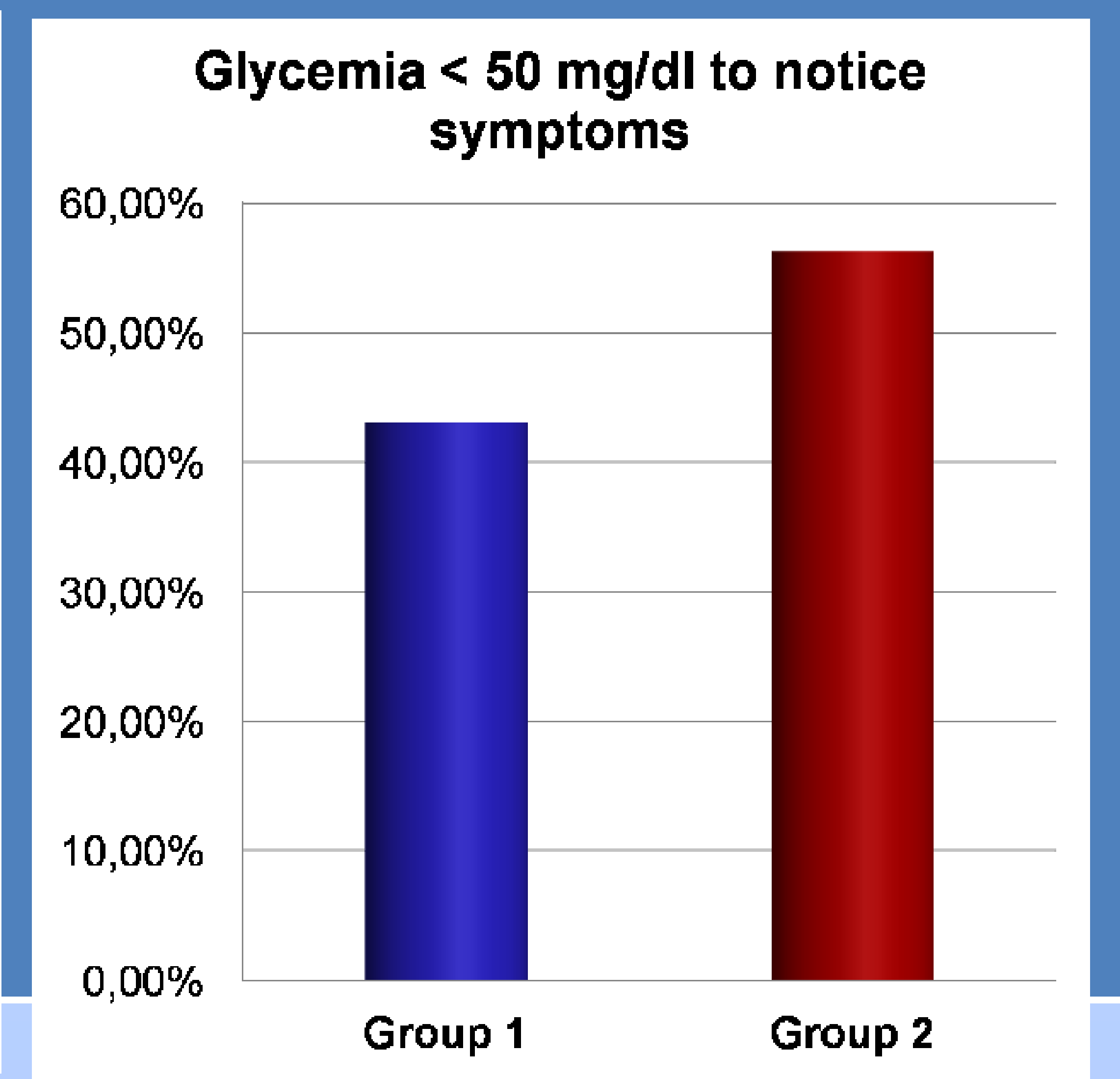

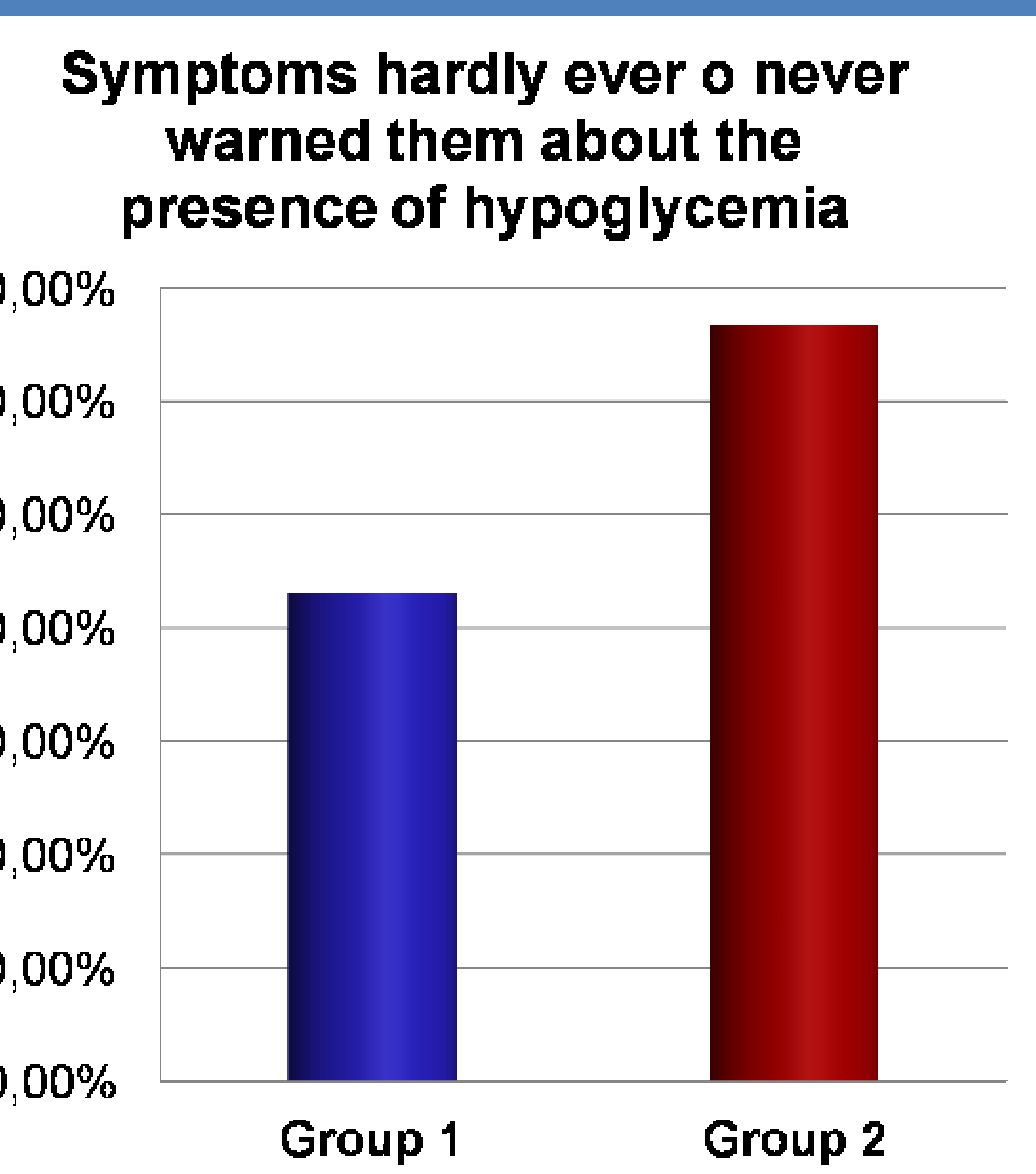

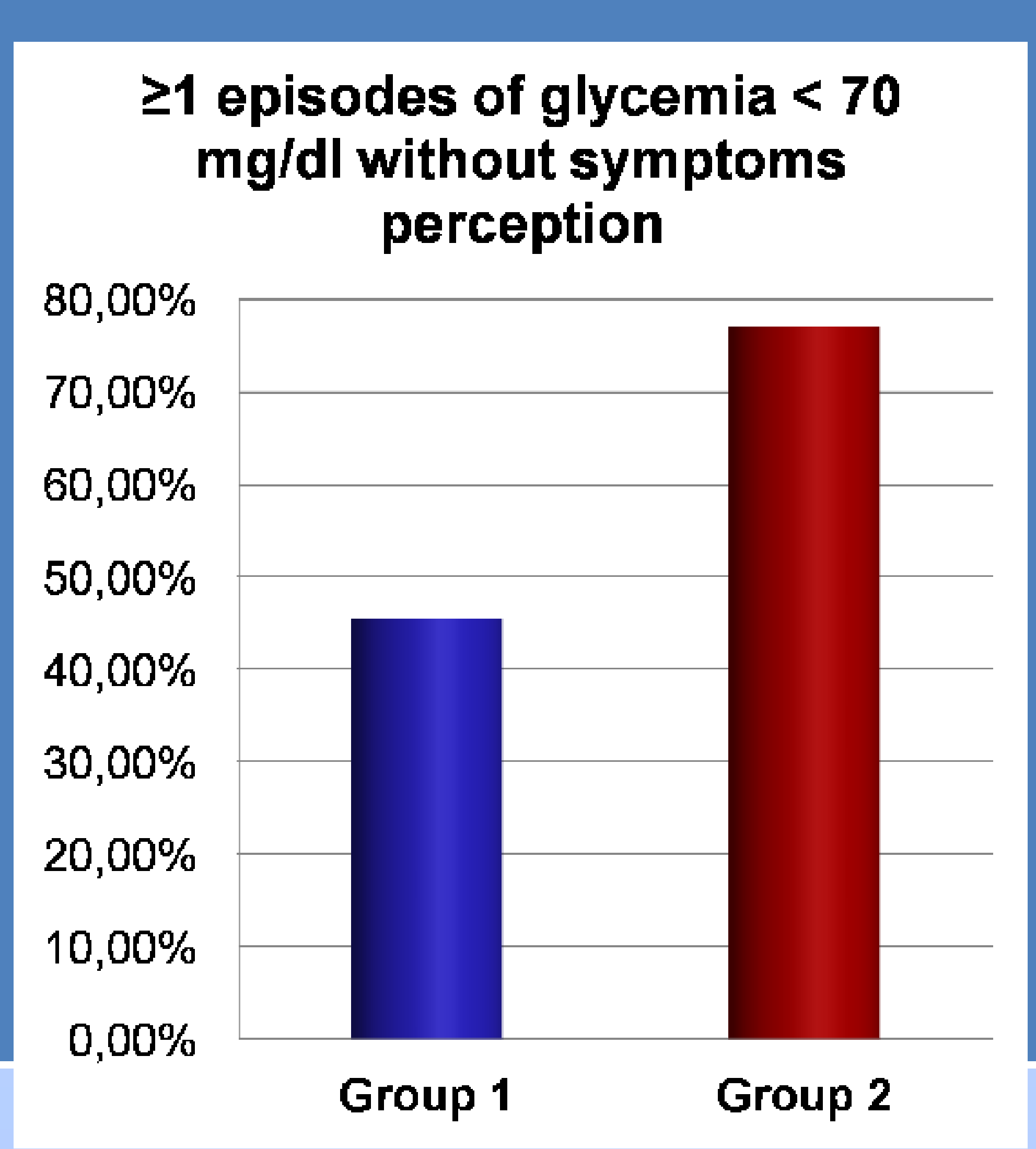

There have not been any significant differences between both groups in diabetic microangiopathy, duration of disease, eating disturbances and insulin regimens (basal-bolus versus biphasic).

\section{CONCLUSIONS}

We have observed a high prevalence of unawareness hypoglycemia in patients with T1DM. Educational strategies are needed to improve their perception of hypoglucemia symptoms 